\title{
Anarquismo e identidades de género en el Uruguay del Novecientos
}

\author{
Anarchism and gender identities in Uruguay of $900 \mathrm{~s}$
}

Inés Cuadro Cawen

Universidad de la República, Uruguay

Recibido: 08/10/2017

Aceptado: 09/11/2017

Resumen: Este artículo analiza la construcción de identidades de género en el anarquismo rioplatense en las primeras décadas del siglo XX. Esto supondrá identificar cómo esta ideología participó en el proceso de emancipación femenina y apreciar las contradicciones, en las representaciones y en los discursos, en torno a los roles que debían desempeñar varones y mujeres en las sociedad que pretendían construir y dentro del propio movimiento. También nos interesa reconstruir el camino seguido por las posiciones de carácter más "feminista" al interior de esta ideología "libertaria", es decir, analizar cómo el feminismo atravesó al anarquismo y se distanció de éste al fin del período de estudio.

Palabras claves: anarquismo, novecientos, mujeres, género, Río de la Plata.

\begin{abstract}
This article analyzes the construction of gender identities in Rio de de la Plata anarchism in the first decades of the 2oth century. This will mean identifying how this ideology participated in female emancipation process, and appreciate contradictions existing in representations and discourses around the roles that men and women should play in the society they intended to build and within the movement itself. We are also interested in reconstructing the path followed by the more "feminist" positions within this "libertarian" ideology, that is, analyzing how feminism went through anarchism and distanced itself from it at the end of the studied period.
\end{abstract}

Key words: anarchism, 1900s, women, gender, Rio de la Plata. 


\section{Introducción}

En las primeras décadas del siglo XX, Uruguay experimentó un proceso importante de reformas que lideró José Batlle y Ordóñez, presidente de la República en los periodos 1903-1907 y 1911-1915. El reformismo batllista procuró, con variado éxito, la nacionalización y estatización de los servicios públicos esenciales, el fortalecimiento de la industria nacional, la extensión de los distintos niveles educativos al mayor número posible de personas y el mejoramiento de las condiciones laborales. Asimismo, se planteó ubicar al Estado como árbitro de los conflictos sociales y dar término a un proceso de secularización que venía avanzando lentamente desde 1861. Durante estas décadas el país experimentó su último crecimiento poblacional significativo producto de las fuertes corrientes migratorias de españoles e italianos. La presencia de mujeres y hombres con una experiencia política y cultural diferente incidió en la construcción ideológica del país. La internacionalización de valores y la defensa de determinados principios políticos alcanzó la discusión sobre qué roles debían desempeñar las mujeres en el despertar del siglo XX y se sumaron los reclamos emancipadores. Surgieron ideas cuestionadoras del sistema político vigente -y sus fundamentos ideológicos- que se proyectaron también en el ámbito femenino.

La inmigración contribuyó al desarrollo de una incipiente industria local y con ella al despertar de la agremiación obrera. Un punto de inflexión significativo en el proceso de organización del movimiento sindical uruguayo, se produjo en 1905 con la creación de la Federación Obrera Regional Uruguaya (FORU). La misma contó con una notoria mayoría anarquista y un marcado carácter internacionalista. La relativa complacencia del gobierno batllista a la presencia de anarquistas contribuyó a que se radicaran en el país exiliados republicanos y anarquistas españoles, incluso muchos que habían llegado en una primera instancia a Buenos Aires y que por la Ley de Residencia que sancionó Argentina en 1902 fueron expulsados de ese país.

El activismo femenino en filas anarquistas fue muy importante: Juana Rouco Buela, Virginia Bolten, María Collazo, entre otras, asumieron un gran liderazgo en las organizaciones obreras. Participaron de mítines y huelgas, escribieron y crearon una prensa obrera y combativa que apostó a una radical emancipación femenina. Propuestas que merecen ser incluidas en los estudios sobre la construcción política y 
ciudadana de las mujeres, pues estuvieron al margen del derrotero seguido por el sufragismo.

Este artículo se inscribe dentro de la renovación historiográfica que viene experimentando el estudio sobre el anarquismo en el espacio rioplatense y en particular por lo que ha supuesto la inclusión de la categoría de género al estudio de esta ideología/movimiento. Una de las historiadoras pionera en la inclusión de las relaciones de género en los estudios sobre el anarquismo es la argentina Dora Barrancos. ${ }^{1}$ A través del análisis de la prensa ácrata, Barrancos identifica dos etapas en el discurso anarquista respecto a las mujeres en los inicio del siglo XX. Un primer momento, que iría hasta los años veinte, caracterizado por una mirada desde el hombre, donde el interés hacia la mujer pasó por su importancia como "mediadora" en el proceso social ya que sobre ella recaía el futuro de las nuevas generaciones. Otro rasgo muy acentuado en el discurso libertario de estas primeras décadas fue su oposición al llamado “feminismo burgués", en el entendido de que éste quería para las mujeres el destino de los hombres, e incluso amenazaba con desplazarlo. De acuerdo con esta historiadora, "el contrafeminismo del feminismo anarquista hasta la década del 20 se sustentó en un discurso que no puso en cuestión la prominencia del hombre, ni las funciones históricas de la 'naturaleza' femenina". ${ }^{2}$ Para mediados de los años veinte, Barrancos identifica un segundo momento, marcado por la difusión de voces femeninas que comienzan a abogar por una "salida propia", por una sexualidad libre y por el derecho a la maternidad autoconsentida. 3

Otra línea de investigación bastante transitada en las últimas décadas ha sido el análisis de los dos periódicos anarquistas editados y escritos por mujeres en la Argentina: La voz de la mujer (1896-1897) dirigido por Virginia Bolten y Nuestra Tribuna (1922- 1925), bajo la dirección de Juana Rouco Buela. Maxine Molyneux, en un temprano trabajo sobre el feminismo anarquista rioplatense, basó su investigación en el análisis de La voz de la Mujer. Esta historiadora estadounidense destaca que la originalidad del mismo estaba "en su carácter de expresión independiente en una corriente explícitamente feminista dentro de los movimientos

\footnotetext{
${ }^{1}$ BARRANCOS, Dora, Anarquismo, educación y costumbres en la Argentina de principios de siglo CONTRAPUNTO, Buenos Aires, 1989; "Mujeres de "Nuestra Tribuna", el difícil oficio de la diferencia", Revista Mora, 1996.

2 BARRANCOS, Dora, Anarquismo, educación ..., op. cit., p. 276.

${ }^{3}$ En otras publicaciones Dora Barrancos centró su análisis en Nuestra Tribuna, periódico dirigido y escrito por mujeres que se publicó en Necochea entre 1922 y 1924.
} 
de los trabajadores del continente". ${ }^{4}$ Este periódico ha sido objeto de análisis en trabajos posteriores como los de María del Carmen Feijoó y Marcela Neri, quienes entienden a esta publicación como una de las primeras en la que se "discutió la especificidad de la situación de las mujeres obreras, explotadas por la sociedad capitalista y oprimidas por el propio sexo". 5

Asimismo, podemos referir a las investigaciones que han tomado como centro de análisis Nuestra Tribuna. Un ejemplo es un artículo de la ya citada Dora Barrancos en el cual, recurriendo al concepto "feminismo relacional" introducido por Karen Offen, analiza las dificultades que tuvieron las mujeres que escribían en este medio para ser aceptadas por sus compañeros anarquistas, así como el rechazo que ofrecieron a las mujeres "feministas" que promovían la igualdad política. A los efectos de nuestra investigación, es de particular relevancia el análisis que realiza esta historiadora de la prédica de Nuestra Tribuna, pues tiene muchos puntos de contacto con el discurso de las mujeres que accedieron a la prensa libertaria montevideana. Pero ellas lo hicieron con más de una década de anterioridad, lo cual nos lleva a matizar los dos momentos cronológicos que identifica Barrancos.

Un tema de especial interés en la historiografía que analiza las cuestiones de género al interior del anarquismo ha sido los aportes de esta ideología en materia de sexualidad. En esta línea son relevantes los trabajos de Mabel Belucci y más reciente en el tiempo los de la historiadora Laura Fernández Cordero. Belucci destaca "que la retórica libertaria introdujo un claro pionerismo en el debate local al proponer la cuestión de la sexualidad y el lugar de sometimiento de la mujer a la autoridad masculina, del Estado y de la religión". ${ }^{6}$ De los escritos libertarios se desprenden duros cuestionamientos al concepto burgués de familia, promoviendo la "libertad de amar", la unión libre, los métodos contraconceptivos y la abolición de la prostitución. No obstante, hubo una clara tendencia a la idealización de la maternidad como función social femenina. Laura Fernández Cordero, en sus estudios sobre sexualidad y emancipación de las mujeres en el anarquismo, propone una relectura del mismo en clave de género, dando cuenta con ello de la centralidad que tuvieron la diferencia

\footnotetext{
${ }^{4}$ MOLYNEUX, Maxine, Ni Dios, ni patrón, ni marido. Feminismo anarquista en la Argentina del siglo XIX, Buenos Aires, Universidad Nacional de Quilmes, 1997.

${ }^{5}$ FEIJÓO, M.C. y NARI, M., "Imaginando las/los lectores de La Voz de la Mujer", en: Fletcher, L. (comp.), Cultura y Mujeres en el siglo XIX, Buenos Aires: Feminaria 1994.

${ }^{6}$ BELLUCI, Mabel, "Anarquismo y Feminismo. El movimiento de mujeres anarquistas con sus logros y desafíos hacia principios del siglo." Todo es historia, $\mathrm{n}^{\circ}$ 351, 1990, 148-157.
} 
sexual y la sexualidad en el ideario libertario. Asimismo, se pregunta sobre el porqué de esa centralidad y advierte que el anarquismo al no "reducir su apelación a una identidad de clase, permitió percibir la opresión en términos más generales e iluminar tempranamente otras zonas de la vida social que se debían también una revolución."7

En Uruguay fue la historiadora Graciela Sapriza quien realizó los primeros trabajos sobre ciertas figuras femeninas de destacada actuación en el anarquismo rioplatense, como Juana Rouco Buela y María Collazo. ${ }^{8}$ De esta misma historiadora existe un trabajo breve que refiere específicamente al vínculo entre las sufragistas liberales y las anarquistas uruguayas en los años veinte. Silvia Rodríguez Villamil también alude a las anarquistas cuando analiza el feminismo a comienzo de siglo XX en Uruguay. Identifica un feminismo obrero, marcado sobre todo por la condición de clase, que en el caso de las anarquistas se centró en cuestionar las bases de la familia burguesa proponiendo el "amor libre", así como criticaron "la educación y la religión como factores retardatarios que pesaban sobre las mujeres". 9 De esta autora también resulta de interés la investigación que realiza sobre las condiciones laborales y materiales de las mujeres obreras en las primeras décadas del siglo XX. ${ }^{10}$

Desde un enfoque que se centra más en los sectores populares y obreristas, podemos mencionar las investigaciones de Jorge Balbis ${ }^{11}$, Yamandú González ${ }^{12}$, Universindo Rodríguez ${ }^{13}$ y Carlos Zubillaga ${ }^{14}$. Estos historiadores en sus respectivos

\footnotetext{
${ }^{7}$ FERNÁNDEZ CORDERO, Laura. "Historiografía del anarquismo en Argentina. Notas para debatir una nueva lectura", A contra corriente, Vol. 11, No. 3, Spring 2014, 41-67; "Queremos emanciparos: anarquismo y mujer en Buenos Aires de fines del XIX", Revista Izquierdas, III, 6, 2010.

${ }^{8}$ SAPRIZA, Graciela, Memorias de Rebeldía. Siete historias de vida, Montevideo, GRECMU/Puntosur, 1988; Obreras y sufragistas: ¿un diálogo imposible?, Montevideo: GRECMU, 1989. RODRÍGUEZ VILLAMIL, Silvia y SAPRIZA, Graciela. Mujer, Estado y política en el Uruguay del siglo XX, Montevideo, E.B.O., 1984. También interesa para ver a las anarquistas actuando en un conflicto puntual, Los caminos de la ilusión. 1913 huelga de mujeres en Juan Lacaze, Montevideo, Fin de Siglo, 1993.

${ }^{9}$ RODRÍGUEZ VILLAMIL, Silvia, "Los 'feminismos' de comienzo de siglo en Uruguay" en: Nuestra Memoria, nuestro futuro. Mujeres e historia. América Latina y el Caribe., Ediciones de la Mujer, $\mathrm{n}^{\circ} 10$, CLASCO, Isis Internacional, 1988.

${ }^{10}$ GONZÁLEZ SIERRA, Yamandú y RODRÍGUEZ VILLAMIL, Silvia. "Mujeres en la historia sindical ¿ausentes, ocultas u olvidadas?", Ponencia presentada en el Seminario - taller "Sindicalismo en femenino: pasado y presente, Montevideo, 8 al 11 de noviembre de 1995, inédito.

${ }^{11}$ BALBIS, Jorge, "La situación de las trabajadoras durante el primer batllismo" en El primer batllismo. Cinco enfoques polémicos, Claeh/Ediciones de la Banda Oriental, Montevideo, 1985., pp. 105-12

${ }^{12}$ GONZÁLEZ, Yamandú, Del hogar a la fábrica ¿deshonra o virtud?, Montevideo, Nordan Comunidad, 1994.

${ }^{13}$ RODRÍGUEZ, Universindo, Los sectores populares en el Uruguay del novecientos, Primera parte (19071911), Editorial Compañero, Montevideo, 1994.

${ }^{14}$ ZUBILlAGA, Carlos, Cultura popular en el Uruguay de entresiglos (1870-1910), Montevideo, Linardi y Risso, 2011.
} 
trabajos se detienen especialmente en las penosas condiciones laborales y de vida de las mujeres; así como también aluden a los reclamos que ellas mismas llevaron adelante y a los debates que provocó esta situación entre las ideologías de izquierda, las organizaciones gremiales y el Estado. En términos generales, estos enfoques contemplan los temas vinculados a las mujeres en el marco del estudio de lo que en la época se denominó "la cuestión social”. En este sentido, Yamandú González identifica los puntos de contacto entre la "cuestión femenina" y la "cuestión social". Para este autor, la "cuestión femenina” se convirtió en un tema de discusión social y externo a las propias mujeres a raíz de los debates sobre la educación y de los cambios que generó la industrialización al incluir a las mujeres como asalariadas fabriles. Estos cambios propiciaron, siguiendo con Yamandú González, "una discusión acerca de la pertinencia y legitimidad de los nuevos roles femeninos confrontados con las funciones tradicionales de la mujer, asignados por la ideología patriarcal dominante." 15

De la prolífica producción de Carlos Zubillaga sobre el mundo del trabajo, el sindicalismo y la cultura obrera, resulta de particular relevancia el capítulo "Género, amor y sexo en tiempos de transformación” de su obra Cultura popular en el Uruguay de entresiglos. A partir de un variado corpus documental, alude a las ambigüedades del discurso obrero en torno al trabajo femenino, la prostitución, la maternidad y el discurso libertario en torno al "amor libre".

La producción historiográfica sobre el anarquismo ha crecido considerablemente en las últimas décadas con trabajos que se centran no tanto en los aspectos ideológicos sino en el universo cultural ácrata y en sus aportes en los cambios de la sexualidad de la época. En Uruguay, sin embargo, continúan siendo escasas las investigaciones de carácter académico sobre el anarquismo y más aun las que priorizan la perspectiva de género en el análisis. Por ello en este artículo nos proponemos profundizar en esta línea. Esto supondrá identificar las contradicciones en las representaciones y en los discursos en torno a los roles que debían desempeñar varones y mujeres en las sociedad que pretendían construir y dentro del propio movimiento. También nos interesa reconocer cómo esta ideología participó en el proceso de emancipación femenina y cómo se vinculó con el incipiente pero

${ }^{15}$ GONZÁLEZ, Yamandú, Del hogar a la fábrica..., op. cit.. 
pujante movimiento feminista liberal. Otra debilidad que presentan las investigaciones sobre esta ideología es que se suele ceñir el análisis a las fronteras estatales. Desde nuestra perspectiva es importante trascender esas fronteras y constatar su porosidad. Más aún cuando estamos estudiando un movimiento político ideológico que se caracterizó por su internacionalismo. El anarquismo llegó al espacio rioplatense de mano de los inmigrantes, mujeres y hombres que llegaban tanto a Montevideo como a Buenos Aires y que se movían de una ciudad a otra, difundiendo sus ideologías y ampliando sus redes políticas. Por ello es de particular relevancia para comprender la organización de las mujeres ácratas hacer un seguimiento de la trayectoria de ciertas mujeres que militaron activamente de un lado y otro del Río de la Plata.

\section{El anarquismo en Uruguay y la "cuestión femenina”}

En la segunda mitad del siglo XIX, el Uruguay inició un proceso de consolidación estatal y de transformación productiva que permitió su inserción en el sistema capitalista mundial. Estas transformaciones se dieron bajo el estímulo del ingreso de capitales y capitalistas extranjeros. Asimismo, a partir de 1870 se produjo la inmigración masiva trasatlántica, sobre todo de italianos y españoles, que impactó significativamente en la sociedad y economía local.

La industrialización en Uruguay fue obra de la inmigración, tanto a nivel empresarial como por la mano de obra necesaria para llevarla a cabo. Conviene tener presente que se trataba de una industria de carácter más bien artesanal que fabril, que apuntaba a un mercado interno pequeño y a satisfacer las necesidades que las importaciones no cubrían. Las leyes de proteccionismo aduanero de 1875, 1888 y 1912 también contribuyeron a este incipiente desarrollo industrial.

Junto con la industrialización se inició el proceso asociativo de los trabajadores. A partir de 1870 comienzan las primeras asociaciones mutuales obreras, como la Sociedad Tipográfica Montevideana y la de Reposteros Franceses (1870), por citar alguna de las experiencias iniciales. Otros obreros optaron por organizaciones de carácter clasista y formaron "sociedades de resistencia" o, influenciados por las organizaciones internacionales socialistas y anarquistas europeas, conformaron en 1872 la Sección Uruguaya de la Asociación Internacional 
de Trabajadores (AIT), que en 1875 pasó a denominarse Federación de Montevideo y que era de tendencia anarquista. Esta organización estaba conformada por inmigrantes que venían con una cultura de lucha política e ideológica europea, que "tenían como punto de partida la lucha de clase contra los capitalistas en procura de una sociedad libre, igualitaria y socialista". ${ }^{16}$ Su prédica se llevó a cabo a través de varios periódicos, revistas y folletos. También mediante la conformación de un circuito político y cultural que combinaba conferencias, fiestas, reuniones, mítines, representaciones teatrales, escuelas y bibliotecas. Esta modalidad de actuación es lo que ha destacado el historiador argentino Juan Suriano, cuando refiere al anarquismo como un movimiento ideológico- político, pero también social y cultural. ${ }^{17}$

En Uruguay, el movimiento libertario se nutrió y fortaleció de la intensa movilidad de sus militantes, quienes voluntariamente a través giras publicitarias o de forma forzada (por extradiciones) recorrieron las principales ciudades del país (Montevideo, Paysandú, Salto, Las Piedras). Figuras de conocida relevancia internacional arribaron al país en estas décadas como Enrico Malatesta, Pietro Gori, Oreste Ristori, Eduardo Gilimón, Joaquín Hucha, Ramón Palau, Ardían Troitiño, entre otros. ${ }^{18}$ Se fundaron múltiples centros de estudio que nucleaban a quienes llegaban y daban cohesión social a los obreros, muchos de ellos con una vivencia de desarraigo importante por su condición de inmigrantes. Los centros fueron un factor clave para la consolidación de una identidad de clase que trascendiera la fábrica, a través de ellos se organizaron tertulias, picnics, conferencias, veladas artísticas y manifestaciones.

En agosto de 1905 se produjo otro punto de inflexión en la organización del anarquismo del país al celebrarse el primer el Primer Congreso Obrero que constituyó la Federación Obrera Regional Uruguaya, en el local del Centro Internacional de Estudios Sociales. La FORU se creó bajo el ejemplo de la FORA argentina - vale señalar que varios exiliados anarquistas de la vecina orilla

${ }^{16}$ GONZÁLEZ SIERRA, Yamandú y RODRÍGUEZ VILLAMIL, Silvia. "Mujeres en la historia sindical ¿ausentes, ocultas u olvidadas?", Ponencia presentada en el Seminario - taller "Sindicalismo en femenino: pasado y presente, Montevideo, 8 al 11 de noviembre de 1995, inédito, p. 65

${ }^{17}$ SURIANO, Juan, Anarquistas: cultura y política libertaria en Buenos Aires 1890-1910, Buenos Aires: Manantial, 2001.

18 VIDAL, Daniel, Florencio Sánchez y el anarquismo, EBO/Biblioteca Nacional/Facultad de Humanidades, 2010. 
participaron de este primer Congreso- y ésta, junto al resto de las federaciones latinoamericanas, a imagen de la vieja Federación Española. Según consigna el investigador Pascual Muñoz "la diferencia sustancial entre ambos momentos organizativos, es que las antiguas federaciones fueron creadas por anarquistas que pretendían desde allí dar sustento, moral, material e ideológico a las distintas organizaciones gremiales, en cambio la FORU nace desde las mismas organizaciones gremiales."19

De acuerdo con las investigaciones de Yamandú González, de forma temprana uno de los medios de prensa de la Asociación Internacional de Trabajadores como La lucha Obrera (1884) comenzó a tratar cuestiones que aludían a las mujeres: su situación social y en particular la cruda realidad de las asalariadas. La expansión económica incrementó la participación de la mujer en el mercado laboral. Sin especial capacitación, los salarios que recibían las mujeres eran muy inferiores al de los obreros varones y ello las convertía "en un ejército de reserva” apreciado por el capitalista industrial, así como una en "competencia desleal” para los trabajadores varones. Un censo de 1889 de Montevideo indicaba que el trabajo femenino representaba un 21, 5 \% de la población activa de la capital y el censo nacional de 1908 registró que las mujeres representaban el 17 \% de la población activa montevideana. Este descenso en la participación femenina se puede vincular a que se estaba en un proceso de recomposición de la fuerza de trabajo, así como por el ascenso socio-económico de las familias de inmigrantes. De todas maneras, es importante tener presente que un número significativo de mujeres realizaba trabajo a domicilio, dato que los censos recogen solo parcialmente. ${ }^{20}$

Las investigaciones historiográficas sobre las mujeres en el mundo del trabajo evidencian que la mayoría de las actividades se asociaban a habilidades consideradas "naturales de su sexo". Según el censo de 1908, un 50 \% de la población femenina económicamente activa se dedicaba al servicio doméstico, otras eran costureras, lavanderas, planchadoras. En la capital solo un 12 \% de los trabajadores de la industria y el comercio eran mujeres. Al respecto, la historiadora argentina Mirta

\footnotetext{
${ }^{19}$ MUÑOZ, Pascual, La primera huelga general en el Uruguay. 23 de mayo de 1911, Montevideo, La Turba Ediciones, 2011.

${ }^{20}$ GONZÁLEZ SIERRA, Yamandú y RODRÍGUEZ VILLAMIL, Silvia, "Mujeres en la historia sindical ¿ausentes, ocultas u olvidadas?..., op. cit.; BALBIS, Jorge, "La situación de las trabajadoras durante el primer batllismo", op. cit.
} 
Lobato sostiene que la vinculación del trabajo femenino con las funciones propias de su sexo incidió para que "la valoración de la destrezas femeninas fuese inferior a la de sus compañeros varones" y esta descalificación se acompañó de un salario inferior. ${ }^{21}$ La penosa situación de las mujeres obreras alarmó a los distintos sectores sociales. Para el cambio de siglo, la "cuestión femenina" era un tema que trascendía al movimiento libertario: desde otras filas ideológicas, católicos, liberales, socialistas trataron el tema y sobre todo buscaron dar respuestas, que en términos generales, aplacaran los ánimos de las propuestas más "feministas". En el Novecientos las mujeres comenzaron a ocupar espacios en el escenario sindical, en la prensa obrerista, en mítines y en proclamas públicas. En la mayoría de los casos, denunciando las condiciones de sus pares femeninas, interpelando a los obreros organizados y procurando concientizar a las mujeres sobre la necesidad de luchar por sus derechos. ${ }^{22}$

Las diversas investigaciones en torno al movimiento ácrata resaltan su mayor compromiso respecto a la emancipación femenina en comparación con las otras ideologías de matriz proletaria. Ello se explicaría, según la historiadora Gloria Espigado, porque el anarquismo "concebido como doctrina general alternativa de emancipación social e individual, habría seguido siendo fiel a la tradición marcada por el socialismo utópico, fourierista u owenista, que mantuvo una concepción liberadora para el conjunto de los seres y no solo de las clases oprimidas". ${ }^{23}$ Es lo que Juan Suriano ha denominado heterodoxia clasista: sin dejar de apelar esencialmente a los trabajadores en tanto éstos eran los sectores más oprimidos de la sociedad y que en sus prácticas alentaban la lucha de clases, el mensaje libertario pretendía ser universalista y no clasista. ${ }^{24}$

\section{Las ambigüedades libertarias}

Las investigaciones que ha realizado Mary Nash sobre el anarquismo hispano han dejado en evidencia las contradicciones de esta ideología respecto a la relación entre los sexos y en particular al lugar en la sociedad que debían ocupar las mujeres.

\footnotetext{
${ }^{21}$ LOBATO, Mirta Zaida, "El trabajo de las mujeres en Argentina y Uruguay", en: Isabel Morant (Dir.) Historia de las mujeres en España y América Latina. Tomo IV. Del siglo XX a los umbrales del XXI, Barcelona, Cátedra, 2006, p. 808.

${ }^{22}$ ZUBILLAGA, Carlos, Cultura popular en el Uruguay..., op. cit., p. 156.

${ }^{23}$ ESPIGADO, Gloria, "Las mujeres en el anarquismo español (1869-1939)", Ayer, 45, 2002.

${ }^{24}$ SURIANO, Juan, "Las prácticas politicas del anarquismo argentino", Revistas de Indias, n² 210,1997.
} 
Siguiendo los postulados de Nash, en el anarquismo se pueden identificar con claridad dos corrientes: una que puso énfasis en el rol maternal de las mujeres -y por ende priorizaba la función reproductiva, en consonancia con los planteos de Prudhon- y otra, más afín con las ideas bakunianas, que denunciaba la situación de opresión del sexo femenino y alentaba su emancipación. Según esta corriente, la independencia de las mujeres pasaba por una incorporación al mercado laboral en igualdad de condiciones al hombre y para ello debían unirse a la lucha sindical para mejorar sus condiciones de explotación. No obstante, quienes defendían la necesaria emancipación de las mujeres lo pensaban dentro de la lucha revolucionaria y no como un objetivo único ni prioritario. Fueron muy escasas las voces femeninas que plantearon como prioridad romper con la situación de opresión de las mujeres. ${ }^{25}$

En la prensa libertaria montevideana se puede constatar cómo conviven estas dos corrientes, aunque la primera con matices pues en términos generales no se hizo una campaña en contra del trabajo femenino. Sin embargo sí se afirmaba que la misión social de las mujeres era la maternidad y por ende, el hogar su ámbito de actuación "natural".

En las primeras décadas del siglo XX, cobró fuerza un discurso cientificista que procuró probar la inferioridad "biológica" de las mujeres respecto a los hombres. Este discurso permeó todas las ideologías. En la prensa libertaria, encontramos algunas alusiones a estos argumentos cientificistas que sustentaban las desigualdades de género como el resultado inevitable de las diferencias biológicas. En marzo de 1907 el vocero anarquista $L a$ voz de los rebeldes, bajo el epígrafe $L a$ mujer e invocando al saber antropológico, afirmaba que la naturaleza había hecho "inferior a la mujer no dotándola de la poderosa inteligencia de los hombres, ni de iguales fuerzas físicas". Sin embargo, se afirmaba que la había dotado "de cualidades superiores que son las consecuencias de sus propias debilidades y de su menor inteligencia". Estas diferencias "naturales" se reflejaban, según el periódico ácrata, "en la división del trabajo", correspondiendo a las mujeres "los cuidados del hogar y la educación de la familia”. ${ }^{26}$

Detrás de esta explicación "científica" de la inferioridad biológica de las

\footnotetext{
${ }^{25}$ NASH, Mary. Rojas. Las mujeres republicanas en la Guerra Civil, Madrid, Taurus, 1999.

${ }^{26}$ La voz de los rebeldes, Montevideo, marzo de 1907.
} 
mujeres estaba el interés de los obreros para que las mujeres no sirvieran a los intereses de la burguesía y volvieran a sus hogares. El discurso de la "domesticidad" atravesó a todas las ideologías en el siglo XIX y buena parte del XX. Se partía de la premisa de que la naturaleza biológica femenina condicionaba su actuación en la sociedad y por ende, era la capacidad biológica de reproducción de la mujer - o sea la maternidad- y los atributos asociados a ella, los que definían el campo de actuación de las mujeres en la sociedad.

Pero así como encontramos expresiones afines al discurso cientificista sobre la inferioridad mental de la mujer, también hubo mujeres ácratas que dando cuenta de una gran agudeza ideológica desmontaron uno a uno los prejuicios que justificaban el servilismo femenino. En 1896 en el periódico obrerista El derecho a la vida, un artículo escrito por una mujer, les espetaba a los burgueses:

\begin{abstract}
"Os vanagloriáis de una pretendida superioridad física e intelectual, citándonos triunfalmente la de vuestros fisiólogos y psicólogos, conclusiones basadas sobre el diferente género de vida que el hombre y la mujer están llamados a desempeñar. ¿Creéis entonces que se puede declarar a un ser inferior solamente porque difiere de otro, sobre todo cuando estas diferencias provienen de la facultad que lo distingue y que determina su función en la vida? Pues bien: yo que soy mujer me creo perfectamente vuestra igual y encuentro mis facultades tan nobles como las vuestras y todos mis órganos tan útiles en la evolución general del gran todo humano". ${ }^{27}$
\end{abstract}

El artículo continuaba dando cuenta de que había muchos "pretendidos amantes de la libertad" que en sus hogares ejercían la autoridad sobre sus compañeras apelando también a esa "pretendida inferioridad de la mujer". Concluía afirmando que no sabía "hasta cuando ciertos hombres que se dicen revolucionarios persistirán en oponerse a nuestra emancipación completa." Emancipación que era inherente a la sociedad que se pretendía construir, pues si triunfaba el ideal libertario, la mujer sería libre e igual al varón.

Del análisis de la prensa anarquista se evidencia con claridad la heterogeneidad ideológica del movimiento libertario, incluso al interior de un mismo medio de prensa. Asimismo, se constata que, en términos generales, los periódicos que contaron con la participación de mujeres en su redacción fueron más explícitos en la necesidad de alentar la emancipación femenina no sólo en el ámbito laboral, sino también al interior del hogar y en la sociedad. Esta heterogeneidad la podemos

${ }^{27}$ El derecho a la vida, Montevideo, julio de 1896, año IV, número 31. 
encontrar en un quincenario dirigido y editado por mujeres como fue La Nueva Senda. En un artículo de enero de 1910 - fecha en que el periódico estaba bajo la dirección de Virginia Bolten²8 - dirigido a las madres obreras, no se hizo hincapié en su “emancipación” sino que su autor procuró hacerles tomar consciencia del costo social que tenía que abandonaran los hogares.

\begin{abstract}
“¿Sabéis lo que representa vuestro trabajo en la fábrica? Pues representa la supresión del trabajo del hombre, a medida que los progresos mecánicos van multiplicándose más, va reduciéndose el número de operarios que con ellas se empleaban para ser remplazados por la mujer y el niño.

Es preciso pues, compañeras, que vosotras nos ayudéis para que nosotros podamos lograr de momento que vuestras horas de trabajo sean disminuidas a fin de que puedan ocuparse más brazos y vosotras tengáis un poco más de reposo y de tiempo para cuidar vuestras familias y para que después podamos llegar con vuestra unión a emanciparnos de la fábrica, para que podáis ser mujeres libres y que viváis dignas de vuestra misión elevada, siendo esposas, siendo madres y no como esclavas y no como instrumentos de explotación". ${ }^{29}$
\end{abstract}

Joan Scott ha demostrado en sus trabajos sobre la construcción de la identidad de la clase obrera en Inglaterra, cómo ésta se hizo desde los varones y por ende supuso como natural una determinada división social del trabajo - según el género- que era aceptada tanto para los hombres como para las mujeres. La equiparación de la productividad con la masculinidad dejó poco espacio para la visibilidad femenina en el ámbito de la producción. 30

En el semanario El Hombre, editado por los Centros de Estudios Sociales y que comenzó a salir en 1916, bajo el título "Misión de la Mujer”, se explicitaba la necesidad de que ésta comprendiera que "el rol más importante de su naturaleza" lo debía ejercitar con "el arte excelso y esencialmente humano: el arte de saber ser madre". Asimismo, superando los discursos esencialistas que fundamentaban en las diferencias biológicas la desigualdad entre hombres y mujeres, se aludía a la necesidad de distinguir entre el "valor natural” y el "valor social” de las mujeres. Respecto al primero, se afirmaba que "las mujeres [eran] idénticas a los hombres ante la Naturaleza [y] como individuos en la Humanidad", pero su "valor social" era "como madre y maestra de generaciones en el seno de la sociedad y la familia".31

\footnotetext{
${ }^{28}$ En el semanario (en los ejemplares a los que pudimos acceder) figura Virginia Bolten como directora después de que Juana Buela tuvo que escapar por la persecución policial. Sin embargo, en su Memoria, Buela afirma que la dirección del semanario pasó a María Collazo, quien sacó 15 números del mismo.

${ }^{29}$ La Nueva Senda, Montevideo, 23 de enero de 1910.

${ }^{30}$ SCOTT, Joan, Género e Historia, México, Fondo de Cultura Económico, 2008, pp. 91 y ss.

${ }^{31}$ Ibídem.
} 
La prédica libertaria de este medio de prensa traduce la necesidad de educación y formación de las mujeres para que desempeñen adecuadamente su rol prioritario en la sociedad: ser madres. Es más, se les reprocha el poco orgullo que sentían por esa tarea, cuando "las facultades de reproducción hacen de ella un factor tan importante como el hombre en la sociedad". ${ }^{2}$

Ahora bien, se alude a que la función social de la mujer radica en la maternidad, pero también se promueve que ella piense y se eduque a la par del hombre. En un artículo titulado "La compañera”, se pone énfasis justamente en la necesidad de que la mujer "se manifieste libremente", de lo contrario seguiría "sufriendo las opresiones y las angustias de quienes se benefician de su ignorancia". Y nuevamente se insiste en que, de no ser así, sería difícil "el avance de los hombres que luchan por vivir sus propias vidas”.33 Se tenía la convicción de que las mujeres actuaban como un elemento retardatario del proceso revolucionario y fue eso lo que motivó una prédica en pro de la educación e incluso de la agremiación femenina.

En términos generales, los varones que escriben sobre las mujeres no reconocen a sus pares anarquistas y terminan invisibilizándolas. Se refieren a las mujeres como un "otro" no incluido en el movimiento ácrata. De la misma manera que los liberales solían describir a las mujeres como seres supersticiosos, fácilmente manipulables por el clero, los anarquistas utilizan expresiones similares. Por ejemplo, ante el éxito de una celebración de Corpus Christi, se preguntaban por qué habían participado tantas mujeres de pueblo. La responsabilidad última la tenían los hombres, esos esposos, padres o hermanos que no habían impedido que sus mujeres participaran en "recorrer las calles en la más vergonzosa de las manifestaciones, encabezadas por hombres que han aceptado representar la negación del sexo”. Los epítetos dedicados al sacerdote vinculados a su poca virilidad u hombría fueron muy frecuentes. Los motivos, varios: su vocación religiosa en una época que ésta se percibía como un asunto de mujeres, su "holgazanería” en tanto no tenían un trabajo económicamente productivo, su voto de castidad en una cultura cuya masculinidad hegemónica está identificada con la conquista sexual e incluso por el uso de sotana

32 "La mujer necesita ideas", El Hombre, n 9, 23 de diciembre de 1916.

33 "La compañera", El Hombre, n' 14, 27 de enero de 1917. 
que era similar a una pollera. 34 En cuanto a las mujeres, el reproche pasaba porque eran capaces de pasar vergüenza en unas procesiones religiosas y no se animaban a "cruzar las calles con altivez cuando las protestas populares son imprescindibles, sino que se esfuerzan en calmar el entusiasmo del hombre cuando este se apasiona en la lucha por la reclamación de sus derechos.”35

La invisibilidad de las mujeres que sí estaban comprometidas con el ideal libertario se hace más evidente en los medios de prensa que no contaban con el aporte femenino. La prensa gremial era expresión de una sociabilidad política y sindical masculina, como sostiene Mirta Lobato, por lo tanto "la visión sobre el trabajo de las mujeres y sus consecuencias se construyó bajo la lente de la mirada varonil." 36

\section{De un lado y otro del Río de la Plata}

En párrafos anteriores aludíamos a la circulación de los activistas ácratas por motivos publicitarios pero también forzados por la extradición o expulsión. En 1902 en Argentina se aprobó la Ley de Residencia, por la cual el gobierno podía expulsar a todo extranjero sospechoso de impulsar huelgas o actos subversivos. Esta ley puso en condición de sospechoso a todos los anarquista, sometidos a una estricta vigilancia y fueron los primeros en ser expulsados. Dada la proximidad geográfica y cultural de Uruguay, varios de los expulsados optaron por cruzar el río e instalarse en Montevideo o en algunas de las ciudades del litoral (Salto y Paysandú). Ambos países comenzaron a compartir prácticas militantes, organizaciones y experiencias laborales, pues fue frecuente la alternancia laboral entre Buenos Aires, Rosario, Montevideo u otra ciudad del interior.

Por otra parte, con el ascenso de José Batlle y Ordoñez a la presidencia de la República en 1903, comenzó un período político caracterizado por el cuestionamiento "progresista" al orden establecido. El batllismo tuvo muchos puntos de contacto con el anarquismo y el socialismo. De acuerdo con los historiadores José

\footnotetext{
${ }^{34}$ Sobre masculinidad en el anarquismo son muy escasas las investigaciones. Un trabajo que aborda el tema en el mundo obrero en general es el de MARTÍNEZ-GONZÁLEZ, Alejandro, "Masculinidad hegemónica en el discurso del movimiento obrero madrileño de fines del siglo XIX y comienzo del XX”, en: http://www.estudiosmasculinidades.buap.mx/num9/masculinidad_h.html, 25 de junio de 2016.

35 La Batalla, Montevideo, 26 de junio de 1919.

${ }^{36}$ LOBATO, Mirta, La prensa obrera, Buenos Aires, Edhasa, 2009, p. 141.
} 
Pedro Barrán y Benjamín Nahúm, más allá de las diferencias ideológicas de fondo, "las tres posturas eran sobre todo manifestaciones de un estilo de vida, el que hacía que se rechazase en lo personal el matrimonio religioso, se viera con simpatía a los 'agitadores' del 'dormido' mundo obrero, se estuviera siempre psicológicamente predispuesto a dar la razón a los 'de abajo', así como a poner en tela de juicio los principios de la moral dominante, desafiándola y burlándose de ella”. ${ }^{37}$ En relación al anarquismo, estos historiadores destacan que fue notoria para los contemporáneos la recíproca influencia entre el batllismo y el anarquismo uruguayo. El diario batllista El Día publicaba con frecuencia escritos y conferencias de socialistas y anarquistas; así como tuvo una prédica de marcado tono internacionalista, "una exclusión consciente de toda manifestación de nacionalismo estrecho, irracional”..$^{8}$ Lo cual lo puso en consonancia con las posturas anarquistas "que enfatizaban en el individuo, en la humanidad y negaban el carácter sagrado a la patria”. ${ }^{39}$ Esta simpatía del batllismo por el anarquismo y las ideologías de matriz proletaria presentes en el país contribuyó a que varios de los expulsados de la vecina orilla encontraran refugio y espacio para continuar su militancia en tierras uruguayas.

Este contexto explica por qué dos anarquistas de actuación significativa en la Argentina, afectadas por la "ley de Residencia", optaran por radicarse en Montevideo: Virginia Bolten y Juana Rouco Buela. En sus Memorias, Juana Buela recuerda que a su llegada a Montevideo se encontró con muchos amigos y compañeros de la Argentina, que al igual que ella habían sido deportados. Entre ellos estaba Bolten y su compañero Manrique González, "Castillejos, Barri, Hucha, Troitiño y tantos otros que festejaron mi regreso a Uruguay, en momentos en que era grande la actividad de los anarquistas en ese país y el movimiento obrero era un valor representativo de los trabajadores, con todos sus gremios bien organizados y mejor orientados por los anarquistas que tomaban parte en sus filas y en su orientación”. ${ }^{40}$ Respecto al período 1910-1914 en que estuvo en Montevideo, señala que fue un período de gran efervescencia anarquista por la buena disposición del

\footnotetext{
${ }^{37}$ BARRAN, J. P. y B. NAHUM, Batlle, los estancieros y el imperio británico, Montevideo, Editorial de la Banda Oriental, Tomo III, 1982, p. 163.

38 BARRÁN, José Pedro y NAHUM, Benjamín, Batlle, los estancieros y el imperio británico, Tomo 1. Montevideo, Ed. Banda Oriental, 1979 y Tomo 2, 1981, p. 47.

${ }^{39}$ Ibíd, p. 45.

${ }^{40}$ BUELA, Juana. Memoria de un ideal vivido por una mujer, Madrid, La Malatesta Editorial, $2012\left(1^{\circ}\right.$ Ed. 1967), pp. 40-58.
} 
gobierno de José Batlle y Ordóñez.41

Para el anarquismo local, la presencia de estas mujeres redundó en una mayor visibilidad de éstas en ámbitos de militancia que tenían una clara hegemonía masculina: en mítines, en el Centro Internacional, en la prensa, etc. También repercutió en la propia movilización de las mujeres, pues estimularon la formación de agrupaciones femeninas.

Virginia Bolten nació en la ciudad argentina de San Luis, en 1890 se radicó en Rosario y junto a su esposo se vinculó a los grupos ácratas. ${ }^{2}$ Enérgica oradora, participó en mítines y dio charlas en distintas localidades argentinas, ganándose el calificativo de "la Luisa Michel rosarina”. Entre 1896 y enero de 1897 redactó en Buenos Aires - junto a Teresa Marchisio y María Calvia- el periódico libertario La Voz de la Mujer, cuyo lema era "Ni dios, ni patrón, ni marido”. En Rosario participó en el grupo Las Proletarias (1899-1900?), que sacó un periódico homónimo al de Buenos Aires.43 Hasta 1905 participó de frecuentes mítines y en las celebraciones del $1^{\mathrm{o}}$ de mayo en distintas ciudades argentinas y en Montevideo. Según consignan Prieto, Fernández Cordero y Muñoz, durante su etapa rosarina mantuvo un contacto fluido con Montevideo y con varios anarquistas radicados en ella, como por ejemplo, el dramaturgo Florencio Sánchez. Asimismo, dictó varias conferencias en los círculos anarquistas montevideanos y participó en asambleas gremiales.

En febrero de 1905, Bolten fue deportada a Uruguay, pocos días después que su marido y unos treinta compañeros. Se instaló en Montevideo junto a su esposo e hijos, continuando desde esta ciudad su militancia anarquista, a través de las actividades del Centro Internacional de Estudios Sociales y escribiendo artículos en diversos periódicos libertarios: La voz del pueblo (1905), periódico salteño que dirigía Sarah Bergara, y los montevideanos El Pueblo (1905), El Obrero (1905), El Combate (1905), Regeneración (1906), La acción obrera (1908) y Tiempos Nuevos (1910). Fue cofundadora del quincenario ácrata La Nueva Senda. Contra toda forma

\footnotetext{
${ }^{41}$ BUELA, Juana, Memorias de un ideal... op. cit., p. 58.

42 TARCUS, Horacio, Diccionario biográfico de la izquierda argentina. De los anarquistas a la "nueva izquierda" (1870-1976), Buenos Aires, Emecé, 2007; ZUBILLAGA, Carlos Perfiles en la sombra..., op. cit.; GUZZO, Cristina, Libertarias de América... op. cit.; Agustina PRIETO, Laura FERNÁNDEZ CORDERO, Pascual MUÑOZ, "Tras los pasos de Virginia Bolten”, Política de la Memoria. Anuario de investigación e información del CeDinCI, $\mathrm{n}^{\circ}$ 14, verano 2013/2014.

${ }^{43}$ Caras y Caretas, no 98, Buenos Aires, 8 de noviembre de 1900.
} 
de explotación y tiranía (1909-1910). En 1905 participó del primer Congreso Obrero que dio origen a la Federación Obrera Regional Uruguaya. Mabel Belucci sostiene que entre 1903- 1907, Virginia Bolten vivió alternativamente entre la Argentina y Uruguay. Entró y salió clandestinamente de la Argentina varias veces, apareció en pueblos del interior, dio conferencias e incluso participó de la creación del Primer Centro Femenino Anarquista de Argentina en 1907 junto con Juana Buela y María Collazo. Para esta investigadora la instalación definitiva de Bolten en Montevideo fue recién en 1907.

Juana Buela nació en Madrid en 1889 y emigró siendo niña a Buenos Aires con su madre y hermano. 44 Comenzó a trabajar en la industria de la vestimenta y se incorporó enseguida -siguiendo los pasos de su hermano- a la militancia obrera y anarquista. Autodidacta, con solo 15 años representó a las obreras de la Refinería Argentina de Rosario en el V Congreso de la FORA. En 1907 junto a Virginia Bolten y María Collazo organizó el Primer Centro Femenino Anarquista Argentino, que tuvo una participación muy activa en la huelga de inquilinos de ese año. Por su participación en ese conflicto fue desterrada a España en enero de 1908. En 1909 volvió al Río de la Plata pero se instaló en Montevideo, integrándose a las actividades del Centro Internacional de Estudios Sociales y fundó junto a Virginia Bolten el quincenario La Nueva Senda. En octubre de ese año fue oradora en la manifestación que se realizó en Montevideo a raíz del fusilamiento de Francisco Ferrer en Barcelona. Se la acusó de haber incitado a "los exaltados" a que se dirigieran a la Legación Española y por lo tanto se la quiso detener, pero logró eludir la vigilancia policial y escapar a La Plata. En 1910 participó en Buenos Aires de las manifestaciones anarquistas en oposición al festejo del Centenario del inicio de la "Revolución de Independencia", fue detenida y entregada a la policía uruguaya. Estuvo presa diez meses y puesta en libertad al asumir José Batlle y Ordóñez su segundo período presidencial. En 1914 se marchó de Montevideo con destino a Francia como polizón y al ser descubierta fue desembarcada en Río de Janeiro, donde vivió alrededor de tres años. En 1918 retornó a la Argentina y continuó desde

\footnotetext{
${ }^{44} \mathrm{Su}$ nombre es Juana Rouco Buela, pero tras ser deportada en 1908 a España y querer regresar al Río de la Plata pasó a usar su segundo apellido. Por eso en la bibliografía e incluso en las fuentes figura en ocasiones como Juana Buela y en otras como Juana Rouco Buela.
} 
allí su militancia anarquista. Dirigió entre 1922-1925 el periódico Nuestra Tribuna.45

En las biografías de estas militantes anarquistas se pueden identificar puntos de encuentro, como por ejemplo su vinculación con el movimiento libertario a través de los varones de sus familias que ya militaban en sus filas y que les facilitaron el acceso al mismo. Sin embargo, en muchos casos, el activismo político de ellas fue superior al de sus familiares varones y/o parejas. La persecución policial y la expulsión les permitieron entrar en contacto con diversas personalidades del movimiento ácrata, así como vivenciar la solidaridad internacional del mismo. El ejemplo más paradigmático es Juana Rouco Buela.

Durante la primera estadía en Montevideo, Buela instaló un taller de planchado en su casa y desde allí dirigió el quincenario libertario La Nueva Senda. Contra toda forma de explotación y tiranía. Participaron de esta iniciativa otras mujeres anarquistas, como María Collazo. Bolten debió asumir la dirección al tercer número, a fines de octubre de 1909, por la persecución policial que sufrió Buela. Aunque este semanario tuvo una vida corta -en mayo de 1910 dejó de salir- su relevancia radica en las figuras que reunió y por ser el primer periódico libertario dirigido por mujeres en Montevideo. ${ }^{46}$ Podríamos citar como antecedentes en el espacio rioplatense, La voz de la mujer (1896-1897/19oo?) en la ciudad de Buenos Aires y Rosario, que tuvo entre sus redactoras a Bolten, así como La voz del Pueblo. Órgano del Centro Internacional Obrero y defensor de la clase trabajadora, semanario salteño, dirigido por Sarah Bergara47 en 1905 y que contó también con la colaboración de Virginia Bolten y María Luisa Campodónico.

En general, la historiografía argentina alude a dos periódicos anarquistas femeninos: La voz de la mujer (1896-97) y Nuestra Tribuna (1922-1925), con unos 25 años de diferencia entre uno y otro. Pero en el transcurso de esos 25 años algunas

\footnotetext{
${ }^{45}$ SAPRIZA, Graciela, Memorias de rebeldia..., op. cit., pp. 55-76; BUELA, Juana, Memoria de un ideal..., op. cit.

${ }^{46}$ En 1912, en el periódico libertario Anarkos, se aludía a que próximamente saldría "La voz de la Mujer”, "un periódico gratuito que tendrá como objetivo publicar artículos de propaganda por la emancipación y preconizando la organización por fábricas y talleres hasta constituir la Federación de Obreras del Uruguay. La encargada Teresa Cocito", Anarkos. Periódico anarquista, 1912.

47 Periodista salteña vinculada a las organizaciones gremiales y a las actividades del Centro Internacional obrero de Salto, promovió la creación de una biblioteca social, así como participó en conferencias abordando el tema de la condición de la mujer en la lucha social o la participación femenina en el movimiento obrero. Antes de dirigir La voz del Pueblo, en 1902, había colaborado en el periódico también salteño El Trabajo. ZUBILLAGA, Carlos, Perfiles en sombra..., op.cit., pp. 40-41.
} 
de sus gestoras como Virginia Bolten y Juana Buela se encontraron en Montevideo y continuaron con su prédica libertaria a través de la prensa en La Nueva Senda. Iniciativa que sumó a algunas uruguayas como María Collazo 48 , quién probablemente influenciada por esa experiencia, en 1915 fundó y dirigió por un tiempo el diario ácrata La Batalla.

¿Qué características tuvo la prédica anarquista a través de La Nueva Senda? Ya en el primer número Juana Buela dirige su pluma a las "Mujeres", y en particular a las madres "que tenéis que dejar vuestros hogares, abandonando a vuestros pequeñuelos, para dirigiros a la fábrica o al taller, para servir durante todo el día de carne de explotación”. Madres que recibían un salario que apenas les daba para "llevar un pan al hogar" y por lo que sus hijos estaban mal alimentados y debían siendo niños salir a trabajar.

\begin{abstract}
"Oh la ley! La une para siempre (según ellos) con un hombre también como ella víctima de la sociedad actual, cuando no resulta un degenerado que en este caso será doblemente víctima, obligada por la ley a obedecerle ciegamente puesto que él se considera patrón y dueño del hogar formado.

De modo que en esta maldita sociedad la mujer tiene que estar continuamente subyugada: primero bajo la férula maternal que la castiga para que la sociedad no critique sus actos, mientras que por otro lado la corrompe; luego bajo el látigo oprobioso del patrón infame y tirano y por último bajo el despotismo de un degenerado cualquiera que con ínfulas de autorizado por la ley y la sociedad, hace de ella una verdadera mártir”.
\end{abstract}

En las palabras de Juana Buela se condensan los distintos ámbitos de explotación y de sometimiento de la mujer obrera: en el trabajo al capital y al patrón varón; en la familia al marido y a la moral burguesa. Por ello, Buela, se dirige a estas madres, incentivando que formen en sus respectivos gremios "un centro llamado de resistencia en donde encontraran albergue todas las que anhelan que este estado de cosas termine cuanto antes y al mismo tiempo para impedir que el patrón cometa con nosotras cualquiera injusticia y hacer valer nuestros derechos de mujer y de

\footnotetext{
${ }^{48}$ María Collazo, nacida en Montevideo en 1884 de un matrimonio de inmigrantes gallegos, desde su temprana juventud se vinculó al ambiente ácrata como periodista y educadora. Se casó con un obrero cigarrero, también anarquista, con quien tuvo cinco hijos. Por unos años se instala en Buenos Aires, donde milita activamente en los círculos anarquistas. Su activa participación en la huelga de inquilinos en 1907 lleva a que la extraditen. En Montevideo participará del diario La Nueva Senda, de la Asociación Emancipación y en 1915 comenzará a editar La Batalla. Desde este diario apoyará la revolución bolchevique, lo que la llevará a alejarse de la FORU. En 1923 participó de la emergencia de la Unión Sindical Uruguaya junto a Roberto Sotelo y otros compañeros. Murió en el Uruguay el 22 de marzo de 1942 a los cincuenta y ocho años. Por más datos biográficos, véase: SAPRIZA, Graciela. Memorias de Rebeldía ..., op.cit.

${ }^{49}$ La Nueva Senda, Montevideo, 18 de setiembre de 1909.
} 
productoras."50

Es significativo que invite a hacer valer sus derechos como mujeres y como productoras. Esa conjunción no es casual, con ella está aludiendo a la doble sumisión de la obrera. Por un lado que reivindique sus derechos al interior del hogar como reproductora y por otro sus derechos en el mundo laboral como productora. A las mujeres obreras, en tanto el eje de la feminidad se construyó en torno a la maternidad, se les negó su identidad de trabajadoras.

En el siguiente número, quien se dirige a "Las mujeres" es Virginia Bolten. Alude a lo escrito por Buela en la edición anterior, comparte la necesidad de que la mujer "pueda lanzarse a la conquista de sus derechos tantas y tantas veces pisoteados en aras de un falso principio de despotismo, más o menos consciente, que sirve de ejido o disculpa a la ya tan discutida y discutible inferioridad mental de la mujer." Pero discrepa con su compañera de redacción en la posibilidad de crear centros de resistencia y una federación femenina, porque entiende que las circunstancias actuales no les permitían contar "con gremios femeninos capaces por su preparación y aptitud”. Por eso, propone algo más modesto: la formación de un grupo “donde se propague sin cesar el principio de libertad para todos, sin más deberes que su conciencia le dicte una vez conocida profundizada su actuación y situación económica y social, ya que la mujer es doblemente esclava: del salario y de los prejuicios.” Es más, su idea trasciende al anarquismo, al proponer una asociación femenina del libre pensamiento, lo cual les permitiría ampliar su campo de acción. Por otra parte, termina dirigiéndose directamente a las anarquistas, al considerar que "esta obra si ha de ser realidad requiere amor y sacrificio, lo que no creo encontraremos en simpatizantes y menos en indiferentes.” 51

Juana Buela responde al artículo de Bolten destacando que las mujeres en esta "región uruguaya" se estaban despertando de un “aletargado sueño". Celebra la iniciativa de la formación de un grupo femenino, "al cual deberían formar parte todas las mujeres que hayan comprendido la necesidad de implantar una nueva sociedad, en la cual los seres puedan vivir libremente y las mujeres podremos ser madres amorosas y leales compañeras del hombre y no víctimas y esclavas como

\footnotetext{
50 Ibíd.

${ }^{51}$ La Nueva Senda, Montevideo, $1^{\circ}$ de octubre de 1909.
} 
actualmente", al tiempo que ya convoca a una reunión en el Centro Internacional. Finaliza la nota recalcando que "la libertad que anhelamos depende solo de nosotras mismas". 52

El discurso de Juana Buela demuestra cómo precozmente al interior del movimiento libertario algunas mujeres entendieron que debían luchar por la doble explotación a la que estaban sometidas. De acuerdo con Mary Nash, fueron estas mujeres las que hicieron "hincapié en que así como la emancipación de los trabajadores tenía que ser obra de los trabajadores mismos, otra máxima del estilo podría comprender que la emancipación de las mujeres debía ser obra de las mismas mujeres." 53

Según narra Buela en sus Memorias, al ser deportada a España en 1908 llegó a Barcelona. Allí pasó unos días con Teresa Claramunt y la llevaron a conocer una de las escuelas de Francisco Ferrer que había en un pueblo próximo. $54 \mathrm{Su}$ posición acerca del separatismo y la autonomía de las mujeres se puede atribuir, sin duda, a la influencia de la anarquista catalana Claramunt, quien unos años más tarde publicó uno de los primeros tratados sobre la condición social de la mujer en España escrito por una obrera. En él, Claramunt explicita que uno de los mayores obstáculos al progreso de las mujeres era el sentido de superioridad de los hombres. Mary Nash señala que "fue una de las primeras activistas sociales que defendió la autoemancipación de las obreras que, según afirmaba, sólo se conseguiría mediante una lucha específica en tanto mujeres". 55

Buela se percibió a sí misma como "emancipada de los muchos y muy grandes prejuicios que rodean a la mujer”, por lo cual estaba en condiciones de estimular que otras mujeres pudieran "liberarse de las cadenas que tan fuertemente [las] oprimen para que unie[ran] [sus] fuerzas" 56 . En ella, la interiorización de los postulados ideológicos del anarquismo, básicamente sus aspiraciones de romper con cualquier estructura de dominación y subordinación en la sociedad, le permitió redefinir su propia identidad femenina y a partir de su propia experiencia vital, construir un

\footnotetext{
52 Ibíd.

${ }^{53}$ NASH, Mary, Rojas..., op. cit.

${ }^{54}$ BUELA Juana, Memorias de un ideal..., op. cit., p. 32 y ss.

55 NASH, Mary, Rojas..., op. cit.

${ }^{56}$ La Nueva Senda, Montevideo, 1909.
} 
nuevo orden simbólico para las mujeres. 57

\section{La Asociación Femenina "Emancipación"}

El proyecto de crear una agrupación femenina que contribuyera a la emancipación de las mujeres, esbozado por Bolten y respaldado por Buela, no prosperó de forma inmediata, pero sí dos años después. El domingo 26 de marzo de 1911, luego de una manifestación en protesta por el aumento del costo de vida, cincuenta mujeres se reunieron en el local de la Sociedad de Obreros Confiteros y Pasteleros en Montevideo y fundaron el centro femenino "Emancipación". Participaron de esta iniciativa las anarquistas María Casal y Candas, Delfa Boatti, María Collazo y Virginia Bolten. 58

Es significativo que estando aún en Buenos Aires, Bolten y Collazo formaran parte de la creación del Primer Centro Femenino Anarquista en 1907. Al igual que lo ocurrido con La Nueva Senda, se evidencia una tendencia a repetir las prácticas de luchas en una y otra ciudad. Pero a diferencia del Centro Femenino Anarquista, "Emancipación" no se define como anarquista. En tal sentido, la Asociación Femenina "Emancipación” es la materialización de la propuesta que hizo Bolten en 1909 de conformar una asociación femenina de librepensamiento que permitiera reunir a un grupo de mujeres comprometidas. Pues este grupo de mujeres que comienza a reunirse a mediados de marzo se "define libre de todo dogmatismo pudiendo formar parte de ella todas aquellas que deseen encauzarse en la corriente de las ideas genuinamente liberales".59 Asimismo, se manifestaron partidarias de la educación racionalista, que permitiría liberar a las mujeres del fanatismo religioso y de la incidencia del clero en sus vidas. Ideales que compartían tanto anarquistas como librepensadoras. También es significativo que estando Buela en Montevideo no haya formado parte de esta iniciativa. Según consigna Graciela Sapriza, la personalidad fuerte y un poco "vanidosa” de Buela generó ciertas rispideces con

\footnotetext{
${ }^{57}$ AGUADO, Ana. "Identidades de género y culturas políticas en la Segunda República", Pasado y Memoria. Revista de Historia Contemporánea, 7, 2008.

${ }^{58}$ PRIETO, FERNÁNDEZ y MUÑOZ, "Tras los pasos de Virginia Bolten”, op. cit., p. 216 y RODRÍGUEZ, Universindo, Los sectores populares, op.cit. pp. 91 y ss. Sobre María Casal y Candal sabemos que formó parte de la corriente anarcosindicalista y que tuvo una participante en el Centro Internacional de Estudios Sociales, verdadero núcleo del anarquismo de Montevideo en las primeras décadas del siglo XX. Cfr. ZUBILLAGA Carlos, Perfiles en Sombra. Aportes a un diccionario biográfico... op.cit.

${ }^{59}$ El Día, "El Feminismo entre nosotros", Montevideo, 14 de marzo de 1911.
} 
algunas compañeras. ${ }^{60}$

Un mes después de haber sido creada, "Emancipación" hizo público su programa. En él se explicitaba que su principal objetivo era la emancipación de la mujer, para ello se proponía combatir la influencia que el clero ejercía sobre ella y prepararla para que pudiera luchar por sus derechos. En el artículo $5^{\circ}$ se precisaba que esta asociación no pretendía “desligarse del movimiento progresista masculino”, por el contario, la intención era trabajar para que las mujeres se pudieran sumar a él. Para ello había que "elevarla al nivel del hombre como productora y convertirla de competidora, en su verdadera compañera, pudiendo así llenar su misión de mujer y madre". Asimismo, proponía "la educación física, moral e intelectual, fundándose escuelas racionalistas para la infancia y nocturnas para adultos y varones menores de 12 años". 61

En abril de 1911 llegó a Montevideo la maestra uruguaya María Abella de Ramírez como representante de la Federación Femenina Panamericana, para instalar la "Sección Uruguaya". Según consigna Universindo Rodríguez, una delegada de esta Federación participó en una de las primeras asambleas de "Emancipación” y les dejó el programa de esta asociación para que valoraran la posibilidad de sumarse a la "Sección Uruguaya" y así aunar esfuerzos en pro de la emancipación femenina. Sin embargo, tras una intensa discusión, "Emancipación" descartó la posibilidad de formar parte de la Federación Panamericana, básicamente por las discrepancias que tenían respecto a la concesión de los derechos políticos. En el diario El Día se hizo una relatoría de lo sucedido en esa asamblea y se señaló que: "la señora Bolten leyó en esta ocasión un discurso antisufragista, opuesto a la Federación Panamericana, sosteniendo la necesidad de no aceptar el programa de acción de aquella asociación.”. ${ }^{62}$ En una entrevista que realizó un periodista a una de sus socias, ésta decía:

“...no aspiramos al sufragio, no queremos ser diputados, no soñamos con una trasformación de los códigos. Nuestro principal propósito es enseñar. [La instrucción racionalista] es la única que hace hombres libres y mujeres aptas para ser sus

\footnotetext{
${ }^{60}$ SAPRIZA, Graciela. Memorias de Rebeldía..., op. cit., p. 71.

${ }^{61}$ Programa y Reglamento de la Asociación Femenina Emancipación publicado en El Día, Montevideo, 25 de abril de 1911.

${ }^{62}$ El Día, 22 de abril de 1911.
} 
compañeras". ${ }^{6}$

$\mathrm{Su}$ prioridad era dedicar su trabajo "a los más miserables: vendedores de diarios, obreras, los que trabajan y sufren la miseria de pan y la otra miseria, más dolorosa si cabe, la ignorancia.” Para lograr atacar a la "ignorancia” expresaron sus intenciones de afiliarse a "la Liga de Instrucción Racionalista”.

"La Liga Popular para la Educación racional de la Infancia”, promovida por el catalán Albano Rosell, realizó una serie de conferencias en 1911 y en junio de ese año publicó un "Manifiesto al Pueblo" en el cual expresaba que la entidad había sido fundada recientemente en Montevideo y contaba con un buen número de adherentes. Sus objetivos eran difundir mediante conferencias y folletería las virtudes del método pedagógico didáctico racionalista, que había encontrado en las “escuelas modernas" creadas por Ferrer sus principales exponentes. En el Boletín que publicaba esta Liga, se constata que la Asociación "Emancipación", había manifestado su adhesión. También lo hizo la Federación Femenina Panamericana.64

En cuanto a su negativa a incorporarse a la Federación Femenina Panamericana, conviene precisar que una de las fundadoras de "Emancipación", María Casal y Candas, se incorporó a la Federación a título personal. Lo que deja en evidencia la heterogeneidad ideológica de la propia asociación, pero también que cuando se pone el foco en la trayectorias vitales hay otros factores que inciden en la toma de decisiones.

En un somero recorrido por la actuación que tuvo el grupo "Emancipación”, se constata la confluencia entre los intereses de las anarquistas y liberales que lo conformaron. A fines de abril de 1911 la secretaria de la Asociación, María Casal y Candas, participó en el III Congreso de Obrero y en mayo apoyaron la Primera Huelga General decretada por la FORU. Estimularon la sindicalización de las mujeres trabajadoras, por ejemplo, ayudaron a la consolidación de la Sociedad de Resistencia de "Obreras Alpargateras", de a la Sociedad de Obreras Aparadoras, y a la formación de la Sociedad de "Costureras y Anexos", entre otras. En esta activa participación del grupo en pro de la asociación de las mujeres trabajadoras,

\footnotetext{
${ }^{63}$ El Día, 19 de abril de 1911.

${ }^{64}$ SOLÁ I GUSSINYER, Pere, "Los grupos del Magisterio Racionalista en Argentina y Uruguay hacia 1910 y sus actitudes ante la enseñanza laica oficial”, 1982, p. 241.
} 
nuevamente encontramos una continuidad con el discurso de La Nueva Senda, cuando insistían en la necesidad de "que quienes amamos las organizaciones nos preocupemos algo más de prestar nuestro pequeño apoyo a esos gremios que pertenecen al sexo femenino, para que se organicen en sociedades de resistencia, así que de esa forma podamos defender con más conocimiento de causa nuestros derechos." 65

$\mathrm{Al}$ mismo tiempo, tuvieron una activa militancia en la campaña nacional por la separación de la Iglesia del Estado. En junio de 1911, María Casal y Candas y Delfa Boatti integraron la Comisión Central que organizó la propaganda de esa campaña, junto a representantes de los partidos Colorado, Socialista, Liberal, las Sociedades Masónicas, el Centro Internacional de Estudios Sociales y de la Sociedades de Resistencia. ${ }^{66}$ Así como participaron del mitin anticlerical organizado por todas estas asociaciones, como respuesta a la tradicional celebración católica de Corpus Christi. "Emancipación" acompañó el mitin con un manifiesto de "adhesión ferviente y entusiasta al movimiento liberal que se inicia a consecuencia del acto de fuerzas de botijas y maniquíes de polleras, sin cerebros ni seres libres”. Además de agregar que lo hacían para evidenciar que no todas las mujeres eran "ratas de sacristía ni esclavas del confesionario." 67

\section{Tensiones entre anarquismo y feminismo}

$\mathrm{Al}$ analizar la labor llevada adelante por la asociación "Emancipación” veíamos que una de las primeras discrepancias con la sección uruguaya de la Asociación Panamericana Femenina, fue la cuestión del sufragio. Respecto a este tema podemos reconocer dos tipos de argumentos. Por un lado, aquellos que encuentran sus fundamentos en las ideologías presentes en esta asociación: el anarquismo y el librepensamiento. El anarquismo rechaza las formas burguesas de hacer política y no concibe la vía electoral como forma de alcanzar un cambio revolucionario. Desde esta perspectiva ideológica es evidente que los anarquistas no van a apoyar las iniciativas femeninas que apunten a la igualdad de derechos políticos. En cuanto al librepensamiento, el énfasis en primera instancia estuvo en la igualdad civil entre

\footnotetext{
${ }^{65}$ La Nueva Senda, 29 de abril de 1910.

${ }^{66}$ RODRÍGUEZ, Universindo, Los sectores populares..., op.cit.

67 "El mitin liberal. Los últimos preparativos. Actos populares", El Día, 7 de julio de 1911. Citado por CAETANO, Gerardo, La República Batllista..., op. cit., p. 68.
} 
varones y mujeres más que en la igualdad política, así como en alentar una educación racionalista que permitiera liberar a las mujeres del dogmatismo religioso. No obstante, a medida que el movimiento sufragista mundial y regional tomó nuevos bríos muchas mujeres adscriptas al librepensamiento se fueron sumando a esta causa. No sucedió lo mismo con las anarquistas; la prédica en oposición al denominado "feminismo burgués" se acrecentó a medida que el feminismo como movimiento político cobraba fuerza. Estas se fueron identificando con un "feminismo relacional", en palabras de Karen Offen ${ }^{68}$, vinculado a las fuerzas sociales que se oponen al orden burgués; las librepensadoras, en cambio, a un "feminismo individual" partidario de la igualdad entre los sexos.

Siguiendo a Offen, no promover la igualdad entre los sexos no implicaba desconocer la necesidad de la emancipación de las mujeres, en materia económica, social y moral. Así los y las anarquistas de principios del siglo XX criticaron con frecuencia las relaciones hombre/mujer al interior de la familia burguesa y propusieron una estructura familiar distinta, pero "insistieron en la necesidad de respetar la cualidad complementaria de los sexos, su distinción e independencia”. En tal sentido, esta autora identifica un tipo de feminismo, a comienzos del siglo pasado, que reconocía diferentes funciones sociales en base a las diferencias biológicas y de acuerdo a las cuales la reproducción y la crianza de los hijos era lo prioritario. Esto no significaba que se renunciara a una formación intelectual y moral para ellas, pues no había una contradicción entre una cosa y otra. No obstante, Offen también reconoce "que los enemigos de la emancipación eligieron ciertos aspectos de las teorías sobre la naturaleza especial de las mujeres, las diferencias fisiológicas y psicológicas, la centralidad de la maternidad y una estricta división sexual del trabajo en la familia y en la sociedad, para apuntalar con ello su continua subordinación”. 69

Por último, conviene tener presente que para fines de la década de 1910 se procesaron una serie de cambios en el escenario político-social nacional e internacional que contribuyeron a un mayor distanciamiento entre ácratas y liberales. En 1916, el batllismo encontró un freno a sus reformas socio-económicas y se inició lo que Gerardo Caetano ha denominado "la República conservadora".

\footnotetext{
${ }^{68}$ OFFEN, Karen "Definir el feminismo: un análisis comparativo", Historia Social. Universidad de Valencia, ${ }^{\circ}$ 9, 1991, pp. 103-136.

${ }^{69}$ OFFEN, Karen "Definir el feminismo...", op. cit.
} 
Durante la presidencia de Feliciano Viera la represión a la clase obrera se hizo mucho más evidente y por ende se rompió el acercamiento ideológico que hubo durante la segunda presidencia de José Batlle y Ordóñez. Por otra parte, los sucesos revolucionarios en Rusia generaron nuevas expectativas y modalidades de acción en el anarquismo rioplatense. Asimismo, la vigencia de la nueva constitución en 1919, que consagró la separación de la Iglesia del Estado, culminó con un largo proceso de secularización. Aspecto que había actuado como elemento aglutinador de liberales y anarquistas una década atrás.

En los años veinte, la prédica se dirigió a mejorar el nivel formativo de la mujer proletaria, ya fuese para contrarrestar la incidencia que el catolicismo continuaba teniendo sobre ella o para que pudiera incidir en los varones proletarios que no estaban a la altura de una posible revolución mundial. La experiencia rusa mostró que el camino revolucionario era posible y radicalizó el discurso ácrata en torno a las formas de hacer política. Por eso se va a producir un distanciamiento con los socialistas, comunistas, batllistas y librepensadores: por considerar que promovían la política electoral que era el camino contrario a la verdadera liberación del hombre. De ahí la férrea oposición a las mujeres feministas que exigían el sufragio. La anarquista María Álvarez 70 escribió una serie de artículos en el semanario El Hombre sobre la mujer y la política que sintetizan con claridad los argumentos que estaban detrás del rechazo libertario a las organizaciones de mujeres que promovían los derechos políticos. Álvarez destaca que la mayoría de las mujeres en el mundo luchan por la obtención de los derechos políticos porque consideran que a través de éstos pueden "conquistar la libertad de la mujer y redimirla." Premisa que se sustenta en la idea de que "la esclavitud femenina viene por leyes hechas por hombres". Pero de acuerdo con Álvarez, "las leyes no son hechas teniendo en cuenta el interés de un sexo o de otro, sino más bien un criterio de clase.” El hecho que confirmaba esta opinión era que los hombres proletarios no habían logrado mejorar su situación social a través del ejercicio del sufragio. Siguiendo con esta línea de pensamiento, los canales tradicionales de la política no eran los que conducirían a la "verdadera libertad". Por eso Álvarez, en sintonía con el pensamiento de líderes socialistas como Clara Zetkin o Aleksandra Kolontai, ponía el acento en la división de

\footnotetext{
${ }^{70}$ Son escasos los datos biográficos de esta anarquista. Sabemos que era uruguaya y que murió en 1924 en Montevideo. Publicó artículos en el semanario montevideano El Hombre, en el semanario bonaerense La Antorcha y en la revista Ahora editada en Montevideo por el Centro de Estudios Sociales "Reformarse es vivir".
} 
clase por sobre la sexual:

"El feminismo parlamentario que busca con el voto hacerlo todo, hay que dejarlo para aquellas que asqueada de los placeres mundano y la holganza, buscan en la política la manera de alcanzar nombre y representación en la sociedad. Bien está esto para ellas que toman esa lucha como distracción, para ellas que conocen de la vida el lado bueno, frívolo y vacío... ¿Pero las hijas del pueblo que harán con votar? Nada”.71

¿Pero cuál era el camino que debían seguir las "hijas del pueblo"? Primó la idea de que debían potenciar la militancia de sus compañeros. Por eso la apelación a ellas era con frecuencia en calidad de madre, esposa, hermana, novia y no como trabajadoras. Pues lo que se les pedía no estaba vinculado a su función productiva sino a la incidencia "moral” que podían ejercer sobre el varón proletario.

\footnotetext{
"Procura merced a tus consejos y ternezas, que los seres que te son queridos constituyan elementos sanos de corazón, decididos y viriles! Que su valor sea digno del cariño que le profesas. No consientas nunca que entre los tuyo haya un miembro desgraciado, cuyo peor castigo sea llevar en pos de si el odioso estigma de cobarde".72
}

En la prensa anarquista y en la obrera, dirigida sobre todo a hombres, se hizo culto a ciertos atributos de masculinidad. El coraje, atributo de virilidad por excelencia, aparecía vinculado a la rebeldía frente a la injusticia del sistema. Cobarde era el obrero que se sometía al patrón y no luchaba por el ideario proletario. Desde esta perspectiva, ser anarquista era un atributo de masculinidad. En otro artículo de 1920, titulado "La mujer frente al momento histórico", se hacía énfasis en la inminente "revolución mundial" que daría "por tierra el orden actual de las cosas" y en la necesidad de que todos los hombres proletarios se sumaran a la causa. ¿Qué se esperaba de la mujer ante esta inminente revolución? Que "levantéis vuestra frente y con heroico gesto de rebelión, obliguéis a los hombres a salir a la calle."73 Declaración que podría suponer concederles un poder excesivo a las mujeres, ser capaces de obligar a sus maridos a actuar conforme a sus deseos. Pero también puede tener otra lectura. De acuerdo con Josep-Vicent Marqués, ser varón en la sociedad patriarcal es ser importante, por lo tanto, solo ellos pueden asumir los desafíos que implica una revolución. A las mujeres, desde esta perspectiva, les está vedado tal protagonismo. Ellas están al servicio de los hombres, ya sea para resolverle las cuestiones

\footnotetext{
${ }^{71}$ El Hombre, Montevideo, 9 de octubre de 1920.

72 “¡Oye mujer! Dedicado a la mujer proletaria”, La Batalla, Montevideo, marzo 1920.

73 "La mujer frente al momento histórico", La Batalla, 22 de octubre de 1920
} 
domésticas o, como en este caso, alentarlos a ser "verdaderamente hombres". 74

En el semanario ácrata La Batalla fueron escasos los artículos dirigidos a las mujeres o que referían a ellas. En 1922 comenzó a aparecer una columna titulada Cartas de Mujeres, en la cual solía escribir Ricardo del Carril bajo el seudónimo de Amalia Boris.75 En ese espacio aparecían cartas supuestamente enviadas por lectoras del semanario. Lo que nos da pistas acerca de que efectivamente eran escritas por mujeres es que figuran planteos radicales sobre el lugar de la mujer en la sociedad y en el proyecto libertario. Por el contrario, los artículos firmados por Amalia Boris reflejan la visión masculina sobre el lugar que debían ocupar las mujeres en la sociedad y en el movimiento ácrata. Veamos algunos ejemplos. En su primera columna, Amalia Boris ahonda sobre cuánto han avanzado los hombres en el camino de la lucha, mientras las mujeres "absortas en nosotras mismas y en seres extraterrenales, los habíamos perdido de vista.". Y aclaraba "no os haremos perder espacio con la crítica del vecindario, el comentario de la moda, o la novedad del casamiento en el barrio." La iniciativa surgía de los varones y por eso en ella se concentraban todos los prejuicios que solían caer sobre las mujeres: religiosas, charlatanas, frívolas, buenas para el cotilleo. ${ }^{76}$

Pero Amalia Boris no solo escribía sino que a veces respondía a alguna de las cartas de mujeres que se publicaban en esa sección. Libertad Quiller escribió expresando su agrado por esta iniciativa que tenía La Batalla y alentaba a las compañeras a luchar o "por lo menos acompañar a nuestros compañeros en todo sus actos que tiendan a mejorar nuestra situación miserable." Y agregaba, "si tenemos el prejuicio del ‘¿qué dirán?’ y no vamos a sus centros de estudios sociales, hagamos como ellos, fundemos nuestras agrupaciones." La respuesta de Amalia refleja cuál era la visión hegemónica del movimiento ácrata sobre el rol de las mujeres en el movimiento. Ante la iniciativa de formar agrupaciones femeninas, escribió:

\footnotetext{
${ }^{74}$ MARQUÉS, Josep-Vicent, "Varón y patriarcado", en VALDEZ, Teresa y José OLAVARRÍA (ed.) Masculinidad/es: poder y crisis, Santiago de Chile, Ediciones de las Mujeres, №24, 1997, Isis Internacional.

${ }^{75}$ La Batalla, Montevideo, $\mathrm{n}^{\circ}$ 355, 4 de abril de 1924. Portada: "Bandera Proletaria" debe ser instrumento de capacitación de la mujer" de Ricardo del Carril [Ricardo del Carril escribía en La Batalla usando el seudónimo de Amalia Boris, le dispararon el 3 de setiembre de 1923, en una asamblea obrera que se discutía la unificación sindical. Murió en Montevideo el 16 de octubre. Agradezco a Andrea Brazuna que me informó sobre el seudónimo de Ricardo del Carril y me cedió las referencias sobre la noticia de su muerte publicadas en el diario La Batalla.

${ }^{76}$ La Batalla, Montevideo, año VII, nº 249, 17 de febrero de 1922.
} 


\begin{abstract}
"El problema social, que mantiene esclavizada a la clase trabajadora, no hace mayores diferencias entre la mujer y el hombre. Unos y otros sufren la maldad del régimen-y nuestros ideales al pugnar por la libertad y la justicia tampoco hace exclusivismo. Esa odiosa separación entre el hombre y la mujer, que también contribuye a la humillación de nuestra clase, debemos terminarla, practicando, trabajando en común por el triunfo de nuestras ideas". .7
\end{abstract}

Más allá de esta resistencia a que se crearan centros exclusivamente femeninos, estos existieron, tanto en Montevideo como en otras ciudades del interior. En 1920, por ejemplo, se creó el Centro Femenino de Oficio Varios en la ciudad de Salto. 78

La columna Cartas de Mujeres fue un espacio que diseñó Roberto del Carril (Amalia Boris) para convocar a las mujeres y didácticamente explicitarles qué se esperaba de ellas en el movimiento ácrata. Sin embargo, como espacio abierto a las mujeres - podían enviar cartas- permitió que otras voces -femeninas- se escucharan. En febrero de 1922 apareció un artículo firmado por Eva Vine de García, que aludía a la cuestión del "amor libre". Defendía tal iniciativa en el entendido de que "toda mujer que se respete ha se sublevarse contra la tiranía e inmoralidad del matrimonio tal como hoy se realiza." Pero aclaraba que el ejercicio del "amor libre" "requería como condición previa que la mujer actúe en el mismo plano de libertad civil e igualdad económica en que el hombre desenvuelve sus capacidades.” Por eso consideraba que "el verdadero feminismo deberá tender a liberar económicamente a la mujer. Solo después de liberarse económicamente, la mujer será libre para amar."79 Un par de años atrás, en este mismo semanario se había publicado un artículo de la anarquista española Soledad Gustavo con afirmaciones muy similares. Consideraba que "el amor libre" no era aplicable en una sociedad como la de su presente, porque la mujer estaba en una relación de dependencia con el hombre. "Todo ser que económicamente dependa de otro, afirmaba Soledad Gustavo, nunca podrá mostrar con libertad su pensamientos y sus deseos. Ahora la mujer ha de aceptar al hombre que se digne a mantenerla, no al que su corazón elija."\$o

\title{
A modo de conclusión
}

\footnotetext{
${ }^{77}$ La Batalla, Montevideo, 10 de mayo de 1922.

${ }^{78}$ MUÑOZ, Pascual, Cultura obrera en el interior del Uruguay (Salto, Paysandú y Rocha 1918-1925), Montevideo, Lupita ediciones, 2015.

${ }^{79}$ La Batalla, Montevideo, 10 de mayo de 1922.

${ }^{80}$ Soledad Gustavo, "La familia en el presente y en el futuro", La Batalla, 30 de noviembre de 1918.
} 
En el Novecientos, arribaron a Uruguay muchos anarquistas con determinadas culturas políticas y experiencias militantes que procuraron difundir e implementar en el país. Algunos llegaron tras la travesía atlántica que supuso la inmigración masiva en esas décadas, otros simplemente cruzaron el Río de la Plata. La apertura ideológica y mental que representó el movimiento político liderado por José Batlle y Ordóñez brindó un contexto favorable para ello.

La investigación sobre el anarquismo desde una perspectiva de género deja en evidencia lo heterogéneo que ha resultado este movimiento ideológico en materia de identidad de género. Pero en términos generales, sin embargo, se partió de un natural dimorfismo sexual que justificó la división de las responsabilidades de cada sexo en la sociedad. El discurso libertario hizo énfasis en la función reproductora de las mujeres, enalteciendo la maternidad como misión natural de éstas. Ello no impidió que las mujeres anarquistas estimularan la agrupación de las mujeres para que defendieran sus derechos como trabajadoras, mejorando así sus condiciones salariales y laborales. Pero no así la igualdad en materia de derechos políticos.

Las voces más radicales en materia de emancipación femenina emergieron de ciertas mujeres que, habiéndose construido su identidad como tales, sobre la base del pensamiento ácrata pudieron tomar conciencia y denunciar su doble condición de reproductoras/productoras, así como la doble dominación que caía sobre ellas al formar parte de una sociedad capitalista y patriarcal.

Los modos de expresar y de construir una "conciencia femenina" que incluyera a la de clase pero la trascendiera se hicieron mediante la prensa. Surge con fuerza una prensa escrita por y para mujeres; así como cobró fuerza, al igual que en otros ámbitos ideológicos, el asociacionismo femenino. La formación de la asociación femenina "Emancipación" fue ejemplo de ello. La presencia en Uruguay de anarquistas con una experiencia militante que trascendía las fronteras nacionales resultó clave para que en el ámbito ácrata local hubiese una mayor visibilidad femenina, porque reprodujeron sus experiencias de lucha llevadas a cabo en Buenos Aires. Surgió una prensa dirigida por mujeres ácratas que estimularon el gremialismo femenino y las asociaciones con objetivos libertarios.

Para fines de la década de 1910, con la emergencia de un feminismo sufragista 
que ya tenía sus propias organizaciones femeninas para expresarse, el discurso libertario se distanció de éste y expresó sus discrepancias. Éstas se fundamentaban en el descreimiento ideológico en la democracia representativa como opción política, pero también en la creencia de que las mujeres que reivindicaban la igualdad política estaban tomando como patrón de "evolución” el masculino. Desde la perspectiva anarquista, el feminismo era sinónimo del sufragismo burgués y por lo tanto cargaba con las connotaciones negativas que la expresión tenía dentro del mundo obrero. $\mathrm{Al}$ respecto, Marilyn J. Boxer sostiene que para fines del siglo XIX el uso del adjetivo burgués se había convertido en un epíteto peyorativo. En tal sentido, la historiadora considera que "por una gran influencia de las ideas marxistas acerca de las revoluciones burguesas, se empleaba para denigrar no solo a individuos, sino, gracias a una especie de corrimiento conceptual y lingüístico, a las ideas y objetivos de un movimiento político específico: el feminismo."81

La experiencia rusa radicalizó el discurso ácrata en torno a su rechazo a las formas de la política liberal y con ello se distanció aún más de los planteos sufragistas. Se puso el acento en la división de clase sobre la sexual, descalificando al movimiento feminista liberal como un "feminismo burgués" de mujeres "frívolas y ociosas", que no conocían las penalidades de las obreras y que aspiraban a invertir los sexos.

En el discurso libertario, la diferencia sexual y la complementariedad social de esa diferencia tuvo un peso muy fuerte tanto en varones como en mujeres. En tal sentido, podemos concluir que más allá de los planteos en torno al "amor libre” y sus reclamos por la abolición de la prostitución que ponían en cuestión la "doble moral burguesa", no correspondió al anarquismo formular un sistema de género alternativo. Algunas voces femeninas, como la de Juana Buela o la de Virginia Bolten, aspiraron a uno que fuese un poco más equitativo.

0000

\section{Bibliografía}

ACKELSBERG, Martha, Mujeres libres, El anarquismo y la lucha por la emancipación de las mujeres, Virus Editorial, Barcelona, 2000

\footnotetext{
${ }^{81}$ Marilyn J. Boxer "Repensar la Construcción Socialista...”, op. cit.
} 
ÁLVAREZ JUNCO, José, La ideología política del anarquismo español (1868-1910), Madrid, siglo XXI, 1991 ( $1^{\circ}$ ed. 1976).

BADINTER, Elisabeth, XY. La identidad masculina, Barcelona, Editorial Norma, 1993.

BALBIS, Jorge, "La situación de las trabajadoras durante el primer batllismo" en El primer batllismo. Cinco enfoques polémicos, Claeh/Ediciones de la Banda Oriental, Montevideo, 1985, pp. 105-127.

BARRAN, J. P. y NAHUM, B., Batlle, los estancieros y el imperio británico. Tomo I, Montevideo, Editorial de la Banda Oriental, 1979; Tomo III, 1982, Tomo IV, 1983.

BARRANCOS, Dora, "Mujeres de "Nuestra Tribuna”, el difícil oficio de la diferencia”, Revista Mora, $\mathrm{n}^{\circ} 2,1996$.

BARRANCOS, Dora, Anarquismo, educación y costumbres en la Argentina de principios de siglo, CONTRAPUNTO, Buenos Aires, 1989.

BELLUCI, Mabel, “Anarquismo y Feminismo. El movimiento de mujeres anarquistas con sus logros y desafíos hacia principios del siglo." Todo es historia, $n^{\circ} 351$.

BELLUCI, Mabel, “Anarquismo, sexualidad y emancipación femenina. Argentina alrededor del 900”. Nueva Sociedad, nº 109, 1990.

ESPIGADO TOCINO, Gloria, "Las mujeres en el anarquismo español (1869-1939)”, Ayer, 45, 2002.

FERNÁNDEZ CORDERO, Laura, "Historiografía del anarquismo en Argentina. Notas para debatir una nueva lectura", A contra corriente, Vol. 11, No. 3, Spring 2014, 41-67.

FERNÁNDEZ CORDERO, Laura, "Queremos emanciparos: anarquismo y mujer en Buenos Aires de fines del XIX”, Revista Izquierdas, III, 6, 2010.

FEIJÓO, M.C. y NARI, M., "Imaginando las/los lectores de La Voz de la Mujer” en FLETCHER, L. (comp.), Cultura y Mujeres en el siglo XIX, Buenos Aires, Feminaria, 1994.

GONZÁLEZ, Yamandú, Del hogar a la fábrica đdeshonra o virtud?, Montevideo, Nordan Comunidad, 1994.

GONZÁLEZ SIERRA, Yamandú y RODRÍGUEZ VILLAMIL, Silvia, "Mujeres en la historia sindical causentes, ocultas u olvidadas?", Ponencia presentada en el Seminario - taller "Sindicalismo en femenino: pasado y presente", Montevideo, 8 al 11 de noviembre de 1995, inédito.

GUZZO, Cristina, Libertarias de América del Sur de la A a la Z, Buenos Aires, Libros de Anarres, 2014.

LOBATO, Mirta Z., La prensa obrera, Buenos Aires, Edhasa, 2009.

LOBATO, Mirta Zaida, "El trabajo de las mujeres en Argentina y Uruguay", en: Isabel MORANT (Dir.), Historia de las mujeres en España y América Latina. Tomo IV. Del siglo XX a los umbrales del XXI, Barcelona, Cátedra, 2006, pp. 804810.

MOLYNEUX, Maxine. Ni Dios, ni patrón, ni marido. Feminismo anarquista en la Argentina del siglo XIX, Universidad Nacional de Quilmes, 1997. 
MUÑOZ, Pascual, La primera huelga general en el Uruguay. 23 de mayo de 1911, Montevideo, La Turba Ediciones, 2011.

MUÑOZ, Pascual, Cultura obrera en el interior del Uruguay (Salto, Paysandú y Rocha 1918-1925), Montevideo, Lupita ediciones, 2015.

NASH, Mary, La mujer en las organizaciones de izquierda en España (1931-1939), Barcelona, Universidad de Barcelona, 1980.

NASH, Mary, Rojas. Las mujeres republicanas en la Guerra Civil, Madrid, Taurus, 1999.

PRIETO, Agustina, FERNÁNDEZ CORDERO, Laura y MUÑOZ, Pascual, “Tras los pasos de Virginia Bolten”, Política de la Memoria. Anuario de investigación e información del CeDinCI, $\mathrm{n}^{0}$ 14, verano 2013/2014.

RAMOS, Ma. Dolores, "La historia social: un espacio de encuentro entre el género y la clase", Ayer, no 17, 1995 .

RODRÍGUEZ VILLAMIL, Silvia y SAPRIZA, Graciela, Mujer, Estado y política en el Uruguay del siglo XX, Montevideo, E.B.O., 1984.

RODRÍGUEZ VILLAMIL, Silvia. "Los "feminismos" de comienzo de siglo en Uruguay" en: Nuestra Memoria, nuestro futuro. Mujeres e historia. América Latina y el Caribe., Ediciones de la Mujer, $\mathrm{n}^{0}$ 10, CLASCO, Isis Internacional, 1988.

RODRÍGUEZ, Universindo, Los sectores populares en el Uruguay del novecientos, Primera parte (1907-1911), Editorial Compañero, Montevideo, 1994.

SAPRIZA, Graciela, Memorias de Rebeldía. Siete historias de vida, Montevideo, GRECMU/Puntosur, 1988.

SAPRIZA, Graciela, Obreras y sufragistas: ¿un diálogo imposible?, Montevideo, GRECMU, 1989.

SCOTT, Joan, Género e Historia, México, Fondo de Cultura Económica, 2008.

SURIANO, Juan, Anarquistas. Cultura y política libertaria en Buenos Aires, 18901910, Manantial, Buenos Aires, 2001.

OFFEN, Karen, "Definir el feminismo: un análisis comparativo", Historia Social. Universidad de Valencia, $n^{0}$ 9, 1991.

VIDAL, Daniel, Florencio Sánchez y el anarquismo, E.B.O./Biblioteca Nacional/Facultad de Humanidades, 2010.

ZUBILLAGA, Carlos, Perfiles en sombra. Aportes a un diccionario biográfico de los orígenes del movimiento sindical en Uruguay (1870-1910), Montevideo, Librería de la Facultad de Humanidades y Ciencias de la Educación, 2008.

ZUBILLAGA, Carlos, Cultura popular en el Uruguay de entresiglos (1870-1910), Montevideo, Linardi y Risso, 2011.

\section{Fuentes}

ROUCO BUELA, Juana, Historia de un ideal vivido por una mujer, Madrid, La Mala testa editorial, 2012. 


\section{Prensa}

La Nueva Senda, Montevideo, 1909-1910.

La voz del Pueblo, Salto, 1905.

El Hombre, Montevideo, 1916-1918.

La Batalla, Montevideo, 1915-1927.

Regeneración, Montevideo, 1906.

El surco, Montevideo, 1909.

La voz de los rebeldes, Montevideo, 1907.

El Anarkos, Montevideo, 1912.

El Día, Montevideo, 1911. 